\title{
EL FENÓMENO DE FRONTERA Y SUS VARIABLES. NOTAS PARA UNA TIPOLOGÍA*
}

\author{
Por \\ Alfredo Jiménez**
}

\begin{abstract}
RESUMEN
Las fronteras han sido y son tan diversas que resulta conveniente la elaboración de tipologías que permitan la formación de conjuntos o clusters relativamente homogéneos. Estas tipologías favorecen el análisis comparativo y el mejor entendimiento de los casos particulares y del fenómeno en general. Se señalan algunas de las variables más significativas que intervienen en estos procesos, con especial referencia a la América de habla hispana.
\end{abstract}

\begin{abstract}
National Boundaries have been and are so varied that is it helpful to create typologies which permit the formation of relatively homogenous groups or clusters. These typologies favor comparative analysis and a better understanding both of individual cases and of the general phenomenon. This article looks at some of the most important variables at work in these processes, particularly in the case of the Spanish-speaking countries of North and South America.
\end{abstract}

\section{INTRODUCCIÓN}

Las tipologías de casos pertenecientes a una misma clase de fenómeno hacen más comprensibles las situaciones concretas y permiten comparaciones razonables y significativas. Además, las tipologías ayudan a entender mejor la naturaleza universal del fenómeno. Destaco aquí unas cuantas variables que configuran tipos de frontera, uno de los fenómenos más abundantes en la historia y en el presente. La cuestion es tan obvia como rica en posibilidades, según los criterios de cada observador. Parto en este

* Una versión preliminar de este trabajo se presentó en el evento "Fronteras en perspectiva internacional", efectuado en la Universidad Autónoma de Baja California los días 17 y 18 de noviembre de 1997.

** Seminario de Antropología Americana, Departamento de Historia de América, Universidad de Sevilla. 
(Insayo de unas cuantas premisas y adelanto algunas conclusiones, advirticndo, en primer lugar, la polisemia del término frontera, cuyo campo de significación es tan amplio que se presta a la confusión si no se aclara de qué tipo de frontera se está hablando.

La frontera puede ser una línea imaginaria que separa países, estados, provincias, departamentos. También puede verse como un espacio físico o como un proceso. Puede concebirse como un final o margen; es decir, el límite de lo propio, más allá del cual comienza lo extraño y diferente; es fundamentalmente, un espacio físico de encuentro e interacción de grupos que están en contacto como resultado de causas muy diversas, que también deben ser objeto de investigación. ${ }^{1}$ La frontera es un fenómeno específicamente humano, muy por encima del sentido puramente instintivo de territorialidad que separa o enfrenta a las especies y a los individuos y grupos de una misma especie animal. La frontera es siempre un asunto de dos, por lo menos. Es una situación real en el espacio y en el tiempo. Sin embargo, es una realidad relativa, porque su definición y evaluación dependen del punto de vista de las partes en contacto. En los fenómenos de frontera cuentan, además de sus protagonistas, los observadores con o sin intereses en el proceso y con mayor o menor influencia por comisión u omisión, así como también los que desde su presente contemplan fenómenos del pasado. ${ }^{2}$ Estas distinciones son importantes, porque los diferentes puntos de vista producen imágenes distintas. La historia como tradición, la política como acción, y las ciencias sociales como actividad académica ofrecen visiones subjetivas, o fuera de contexto, o contradictorias, y no sólo diversas y complementarias, que esto último es natural y conveniente. Cada sociedad - sobre todo si es parte interesada-produce estereotipos, juicios y prejuicios que sirven de apoyo a determinadas políticas y alimentan ciertas actitudes y conductas colectivas. ${ }^{3}$

La frontera ofrece un campo inmenso de observación, análisis e interpretación de la conducta humana y pone de relieve aspectos fundamentales del sistema cultural. Las situaciones críticas, excepcionales - características de las fronteras- sacan a la luz lo que normalmente está oculto,

\footnotetext{
1 Ver la excelente introducción y las contribuciones seleccionadas por David J. Weber y Jane M. Rausch, eds. (1994). Sobre terminología, ver el ensayo de Paul Kutsche (1983); son de mucho interés para el área las numerosas contribuciones recogidas en esta obra colectiva. 2 Cada tiempo juzga las situaciones anteriores, y estos juicios pasan con frecuencia a formar parte de la tradición histórica. Hoy todos somos observadores a través de los medios de comunicación de lo que sucede al instante en una sociedad planetaria abundante en conflictos fronterizos. La intervención de terceros es más fuerte y evidente que nunca, y el papel de autoridades supranacionales, como las Naciones Unidas, resulta decisivo en los procesos de frontera.

3 Ver para la American Frontier y la frontera hispano-mexicana Alfredo Jiménez (1996).
} 
disimulado o implícito. Los conflictos sociales, que son parte consustancial de los procesos de frontera, ponen a prueba la funcionalidad de las culturas en relación con cada uno de sus grandes aspectos o subsistemas, desde lo económico hasta las creencias y el sistema de valores.

La interacción social en espacios de frontera produce transformación, adaptación, innovación, rechazo, aceptación, asimilación, sincretismo, mestizaje biológico, extinción cultural y física. El estudio de fronteras es una manera de enfocar el fenómeno universal del contacto entre sociedades con culturas diferentes, y los procesos de cambio subsiguientes. La antropología tiene una larga tradición en este campo en el que actúan, generalmente, una sociedad dominante y otra dominada dentro del marco de un proceso colonial. $^{4}$

El número de variables que intervienen en los fenómenos de frontera es muy alto. Pueden ser principales o secundarias, dependientes o independientes, y cada una de ellas es susceptible de descomponerse en subvariables. Unas y otras deben analizarse en su conjunto y en relación con las constantes. Se destacan a continuación las variables más universales y algunas de las más significativas con mención de situaciones reales del pasado y del presente.

\section{ESPACIO Y TIEMPO}

Espacio y tiempo son las dos grandes variables de todo fenómeno humano. De acuerdo con la tradición histórica, e incluso con la mitología que muchos pueblos han elaborado de su expansión, la frontera es esencialmente un territorio, un espacio físico. ${ }^{5}$ La frontera se ve y se palpa, es una tierra que está más bien lejos, un paisaje que se contempla con los ojos del cuerpo. La frontera es el medio natural donde se produce el encuentro y la interacción; un ecosistema, o una variedad de ecosistemas, habitado por una población que se ve invadida por otra, o que vive en los márgenes o periferia de otra sociedad con la que mantiene determinada relación. El fenómeno de frontera afecta al medio natural, y viceversa. En la naturaleza hay accidentes permanentes, como cordilleras y ríos, pero el ecosistema siempre es dinámico. La imagen popular de la frontera es la de un espacio a ocupar y dominar, y en la práctica van unidas la conquista de la población con la conquista del territorio; es decir, la explotación tanto de los recursos

\footnotetext{
4 Una amplia selección de trabajos sobre esta problemática y su tratamiento teórico la encontramos en Alfredo Jiménez, comp. (1997a).

5 La formulación más temprana y de mayores consecuencias sobre el fenómeno de la frontera la hizo Frederick Jackson Turner (1894).
} 
humanos como naturales mediante las transformaciones necesarias o inevitables. La historia de España es excepcionalmente rica en fenómenos de frontera, tanto en la Península como en América. Por ésta y otras razones, serán frecuentes en este ensayo las referencias al mundo hispánico (Ver Jiménez 1997b).

La península Ibérica, que por un tiempo fue frontera del Imperio Romano, vivió siglos después otro fenómeno de frontera: el choque de la civilización islámica con la cristiana. Fue una frontera movible constituida por un gran espacio de tierra que separaba y comunicaba. Tras la invasión en el año 711 de gente venida de África, y del consiguiente repliegue cristiano hacia el norte, se inició la reconquista del territorio. Los continuos vaivenes, con tendencia general hacia el sur, mantuvo durante ocho siglos una franja de tierra de nadie o tierra quemada. La deforestación, tan visible y grave en la España actual, se debe en gran parte a la destrucción del espacio físico por razones de ataque y defensa.

A partir del siglo XVI, España inicia en las Américas el mayor y más sistemático proceso imperial o colonial de la historia, si atendemos a la extensión geográfica y a las consecuencias de todo tipo. Fue un proceso de conquista y aculturación, de simbiosis, que en todas las áreas constituyó, al menos en un primer tiempo, un fenómeno de frontera. En muchos casos, el medio natural era hostil para los españoles, o nada adecuado a su tecnología y a sus intereses, por lo que tras dominar a la población había que conquistar la selva, el desierto, la puna. Como al indígena se le consideraba salvaje o bárbaro, hubo que civilizarlo al mismo tiempo que se domesticaba o transformaba la naturaleza. Fue también de extraordinaria importancia la introducción en el Nuevo Mundo de especies animales y vegetales que alteraron la economía y crearon situaciones nuevas en todas las regiones, incluidas las áreas de frontera. Por ejemplo, la incorporación del caballo a la economía y guerra de las poblaciones nómadas que habitaban la frontera norte de México.

$\mathrm{La}$ variable espacial puede considerarse como distancia física entre metrópoli y frontera, entre núcleo y periferia. Esto sería una visualización lineal del espacio. Las fronteras de la América española estaban a cientos, miles de kilómetros de los núcleos de poder, sin contar la distancia con la metrópoli peninsular. No hay otro caso en la historia, anterior a la Revolución Industrial, de unas fronteras centenarias separadas físicamente por un océano, y al mismo tiempo conectadas en todos los aspectos con la metrópoli por medio de una poderosa burocracia. ${ }^{6}$

6 El camino real de tierra adentro - de la Ciudad de México a Santa Fe de Nuevo Méxicofue durante siglos una vía de comunicación por tierras de frontera. Más extradordinario aún 
La variable espacial puede también considerarse como extensión o superficie. Cuando una frontera es grande y lejana, su control resulta difícil o imposible. Estas fronteras se convierten en fuente de problemas para la sociedad dominante y en tragedia para los grupos teóricamente dominados. El saldo económico suele ser muy negativo, y el interés por mantenerse en la frontera puede tener otras motivaciones como son las religiosas o las puramente políticas. La frontera norte del México colonial es una buena ilustración de conflicto secular con población indígena y con potencias rivales. $^{7}$

La posesión de un territorio muy extenso también abre, a la inversa, muchas y largas fronteras. Es la historia de China bajo la amenaza constante de ser invadida. La famosa muralla, construida para cerrar el paso a vecinos peligrosos, es una barrera artificial de tal magnitud que afecta al paisaje natural y es visible desde los satélites. Fue una barrera de puertas adentro, levantada para defenderse y no para avanzar, la negación de la frontera como espacio de comunicación. Por otro lado, la falta de espacio vital, o la apetencia de nuevos o mayores recursos, o la ambición política, o los problemas internos, han movido a muchas sociedades a crear espacios de frontera. Pensemos en la tradicional política imperialista del Japón para aumentar su espacio vital a costa de sus vecinos, o en la creación de enclaves de emigrantes campesinos en países tan lejanos como Perú o Bolivia. La expansión de Estados Unidos hacia el oeste se ha explicado como el funcionamiento de una válvula de escape (safety valve) para la corriente migratoria europea y para la población ya asentada en la costa atlántica. Más que las proclamadas aspiraciones de extender la libertad y la democracia, el gran motor de la marcha hacia el oeste fue la existencia de tierra (free land) por la que no había que pagar, o era muy barata, o no tenía dueño, porque sólo la habitaban los indios. Así nació y se extendió la American frontier, según la concepción de Turner. ${ }^{8}$

Hay fronteras que son espacios enquistados, en el sentido biológico del término. Espacios, pequeños que crecen anormalmente, o existen en condiciones anormales dentro de un organismo. La proximidad entre las partes es tan grande que la relación resulta inevitable e intensa, y los

es el caso de las fronteras hispanas en un mundo de fronteras como el sureste asiático. Las Filipinas estuvieron separadas de la metrópoli por dos océanos, con la comunicación entre el Pacífico y el Atlántico a través de la ruta terrestre Acapulco-Veracruz.

7 Ver en relación con la guerra entre españoles e indios la obra general de Philip Wayne Powell, y especialmente Soldiers, Indians, and Silver (1952). La mejor y más reciente síntesis sobre la frontera norte del imperio español, aunque prácticamente limitada a territorios que actualmente son parte de los Estados Unidos, es el libro de David J. Weber (1992).

8 Sobre el concepto de safety valve aplicado a la frontera angloamericana ver Ray Allen Billington (1966:29 y passim). 
conflictos suelen ser permanentes. España tiene actualmente en la península la colonia británica de Gibraltar, y en el norte de África están las ciudades españolas de Ceuta y Melilla, anteriores en su fundación y población al nacimiento del Reino de Marruecos, pero enquistadas en territorio marroquí. ${ }^{9}$ Un caso claro de territorio enquistado ha sido la zona del canal respecto de la República de Panamá. La imposibilidad de la corona española de controlar las innumerables islas del Caribe creó también espacios enquistados que, en términos culturales, lingǘsticos y raciales, persisten hoy. Casos evidentes son Haití y Jamaica respecto del Caribe hispánico. Hong Kong, bajo su nueva situación, no deja de ser un quiste en la enorme China, un extraño experimento de coexistencia de dos sistemas dentro de una misma nación. Se ha suprimido la frontera como línea política, pero persisten las fronteras socioeconómicas e ideológicas, no sabemos por cuanto tiempo.

Hay espacios geográficos dentro de los cuales existen varias fronteras representadas por la interrelación de más de dos poblaciones, cada una con su historia y su cultura, sus problemas y aspiraciones. El suroeste de los Estados Unidos es ejemplo de esta situación. Desde hace varios siglos, esta región es espacio de encuentro e interacción de indios y europeos. Pero la población indígena era y es diversa (pueblos apaches y navajos); y entre los europeos hay que distinguir entre españoles y anglos, más los que hoy se clasifican como hispanos, chicanos, o mexicanos, según criterios y circunstancias. No hay dentro del suroeste fronteras nacionales y, sin embargo, es un caso complejo de fronteras socioculturales. Podríamos hablar de una frontera poliédrica porque cada grupo se enfrenta a varias caras o culturas. Situaciones similares, mucho más dramáticas, se dan en la antigua Yugoslavia y, en general, en los Balcanes, una región donde chocaron hace siglos dos civilizaciones que se han fragmentado en religiones y en nacionalidades con lenguas distintas. El cercano oriente es otra región de fronteras vivas, con su máxima síntesis en una ciudad como Jerusalén. En estas situaciones extremas, los espacios de interacción son barrios y las fronteras físicas pueden estar definidas por calles.

La segunda gran variable, inseparable del espacio, es el tiempo. Mencionemos en primer lugar la duración como atributo del tiempo. La vida de una frontera puede inscribirse en un tiempo largo, medio o corto, por

9 Los tres casos españoles son además espacios dentro de los cuales coexisten poblaciones de lengua, religión, cultura y raza distintas. Ceuta y Melilla se han convertido en vía de paso o escape para una migración clandestina procedente de Marruecos y países al sur del Sahara. Unos cuantos kilómetros de mar hacen el papel de río grande para unos emigrantes que son más que espaldas mojadas, pues muchos encuentran la muerte en las aguas del estrecho de Gibraltar. 
usar la terminología de los historiadores. Al tiempo largo pertenecí́ la frontera cristiano-musulmana de la península Ibérica. La frontera de los Estados Unidos, en la concepción de Turner, pertenecería al tiempo medio. ()tras fronteras, como las que han resultado de la falsa descolonización de África, o de la reorganización del espacio de la antigua Yugoslavia, pertenecen al tiempo corto, porque acaban de surgir y no sabemos cuánto durarán ni en qué condiciones. Una frontera puede nacer de forma repentina. Todo el Nuevo Mundo se presentó de golpe como frontera ante la Europa del siglo XVI. ${ }^{10}$ Las exploraciones relámpagos de los españoles, seguidas en general de rápidas conquistas, crearon también de repente numerosas fronteras regionales. En otros casos, los orígenes de una frontera no son claros y forman parte de un pasado nebuloso.

Otra subvariable del tiempo es la distancia en relación con el observador, que en nuestro caso es el tiempo que media entre el fenómeno histórico y el presente absoluto. En la medida que fuera cierta la afirmación de Turner de que la American Frontier, la frontera del oeste, había terminado en 1890, estaríamos a un siglo del final de un fenómeno que destaca como ningún otro en la historia y formación de la nación norteamericana. Pero no olvidemos que los efectos de una frontera pueden persistir en muchas formas y grados más allá de su propia vida. La historia se convierte así en fuente de conocimiento para el análisis de situaciones presentes y posible solución de conflictos.

Aunque el tiempo es un continuum, hay en el tiempo histórico ritmos o distintas velocidades, que hacen que las situaciones se estanquen o cambien en periodos muy variables. Hay fronteras estables por mucho tiempo o por tiempo indefinido; otras son inestables de manera permanente. Las fronteras conflictivas son como volcanes que pueden estar apagados, o activos de manera intermitente, o entrar en erupción violenta de forma inesperada. Una ojeada al actual panorama internacional muestra la abundancia de estas situaciones, y los papeles contradictorios que desempeña la política, ya sea provocando el conflicto o intentando reducirlo, o ambas cosas al mismo tiempo, porque en estos procesos se entrecruzan ideologías, ambiciones políticas, e intereses económicos, a veces tan criminales como el tráfico de armas. En resumen, cualquiera que sea el ritmo o tempo de evolución de una frontera, o por muy firme que sea su estabilidad, las fronteras son siempre dinámicas - como dinámicas son las culturas actuantes-, de ahí la necesidad de tener en cuenta la variable temporal para cualquier referencia $o$ análisis.

\footnotetext{
${ }^{10}$ Esta fue la tesis de Walter Prescott Webb (1952).
} 


\section{SOCIEDAD Y CULTURA}

Hay otras variables que son específicamente humanas aunque, naturalmente, actúan en el marco de las dos variables universales de espacio y tiempo. El aislamiento de estas variables es mucho más difícil y convencional. En una primera aproximación destacan la sociedad y la cultura, cuya introducción produce un cuadro complejísimo de situaciones, una casuística casi infinita. En este contexto, el análisis de los fenómenos de frontera exige la distinción de niveles de complejidad social, que van desde la organización en bandas de cazadores-recolectores hasta los estados e imperios, que a su vez pueden ser anteriores o posteriores a la Revolución Industrial. A toda sociedad corresponde una cultura, que identificamos por su lengua, creencias y sistema de valores, trayectoria histórica, sistema político, y otras manifestaciones. Por supuesto, hay una estrecha relación entre cultura y sociedad, sobre todo en lo que se refiere a tecnología y economía.

En la conquista española de América, y en la posterior colonización, actuó una constante y hubo muchas variables. La constante fue, precisamente, la cultura de los españoles, expresada en una lengua, una religión, un sistema de valores y una misma política imperial para todos los territorios. La acción concreta varió según regiones y circunstancias, pero los objetivos finales eran los mismos. El indio, por el contrario, presentaba la gama completa que va desde las bandas nómadas a los estados e imperios, pasando por la organización tribal y los señoríos o cacicatos. En todos los casos hubo al principio una frontera en la forma que aquí se ha definido, pero la frontera fue más evidente y duradera, y más dramática, cuanto mayor era la diferencia de niveles de complejidad sociocultural. La frontera entre sociedades complejas y sociedades simples termina generalmente con la extinción física de estas últimas. La interdependencia entre el grado de simplicidad o complejidad, por un lado, y el tamaño de las poblaciones, por otro, es muy grande. La demografía, por tanto, es otra variable muy significativa en el inicio de un proceso de frontera, durante su evolución, y al final del proceso, si se ha producido.

Las fronteras más evidentes y duraderas son las creadas por la gran diferencia entre las variables sociedad-cultura de cada población. Por el contrario, las fronteras entre sociedades muy afines son difíciles de advertir. En los países de Europa occidental las fronteras son poco más que la línea que marca la soberanía política. Los conflictos son disputas o rivalidades entre vecinos, a veces guerras muy crueles, pero no existen fronteras en el sentido que aquí estamos utilizando, porque se trata de países pertenecientes a una misma civilización, la occidental y cristiana. Las verdaderas 
Ironteras de Europa han sido y son fronteras entre civilizaciones: el mundo islámico procedente del norte de África; el poder turco, también islámico, a través de la vía del Danubio.

Las potencias europeas reprodujeron en América sus rivalidades, pero no establecieron verdaderas fronteras entre sí. La prueba de que eran conflictos políticos y económicos entre iguales es que los territorios se intercambiaban, se devolvían, se vendían y compraban, como en los casos de Florida y Louisina. En el lote iban a veces territorios europeos como la isla española de Menorca en el archipiélago de las Baleares. Esas fronteras americanas fueron o dejaron de ser fronteras por simples acuerdos y paces firmados en Madrid o París. Por el contrario, España, Francia, Inglaterra, y en su momento Estados Unidos, sí establecieron fronteras con las poblaciones indígenas, de las que se sentían separados por sociedad y cultura. Al mismo tiempo, el indio veía a todos los blancos como un enemigo común, extraño a su mundo. Por diversos motivos y coyunturas, los indígenas se sumaban a veces a una potencia u otra, pero el indio no dejaba de ser indio, y todo hombre blanco, de cualquier nacionalidad, era para ellos un ser distinto.

Las anteriores observaciones introducen en el esquema otra variable de especial relevancia en la historia, aunque sin ninguna base científica. Hablamos de la raza. Un factor puramente biológico, desacreditado hoy por su falta de objetividad científica, tradicionalmente asociado con algo tan irrelevante como el color de la piel, ha actuado de manera determinante en los procesos de frontera. Desde el etnocentrismo europeo, trasladado a las Américas, en particular a Estados Unidos, la frontera se ha visto como el choque del hombre blanco con el otro. La llegada de población africana, el mestizaje biológico, y la aparición de nuevas entidades étnicas han multiplicado, en la forma y en el fondo, las fronteras de las Américas, quizá como en ningún otro continente. En definitiva, la raza es otra variable que desempeña un papel a veces dominante en los fenómenos de frontera. Puede hablarse, lamentablemente, de fronteras de color. La conjunción de raza, lengua y religión proporciona a los grupos un poderoso sentido de identidad, que puede ser positivo para su propia afirmación, pero cuando las tres variables se califican negativamente desde fuera, la discriminación también es mayor y las fronteras étnicas se convierten en espacios insalvables y, con frecuencia, en fuente de los más graves conflictos sociales.

\section{EL SISTEMA POLÍTICO}

La política es parte del sistema cultural y vertebra en gran medida el sistema social, pero su influencia en relación con las fronteras es tan grande 
que puede considerarse en muchos casos como una variable independiente. Las fronteras surgen casi siempre como consecuencia de una decisión política; es decir, como una acción desde el poder. De manera similar a como la historia más convencional era una historia de guerras entre países, la frontera se ha visualizado tradicionalmente como la situación creada por una sociedad al extender sus límites más allá de su propio territorio a costa de otros grupos o sociedades. Estas expansiones, generalmente violentas, crean un espacio que se convierte para la sociedad invasora en territorio de frontera, al menos por algún tiempo. Pero la frontera es siempre un fenómeno cultural mucho más complejo, de aquí la importancia de considerar los efectos combinados de diversas variables. Detrás de la decisión política hay motivaciones que a veces pueden ser justificaciones más o menos cínicas o sinceras. Para los españoles, la frontera por antonomasia en las Américas fue el espacio donde las diferencias culturales con el indio eran más hondas, y el objetivo pacificador y evangelizador resultaba más difícil, por no decir imposible. Para Estados Unidos, la frontera infinita hacia el Pacífico era, aparentemente, una oportunidad de extender los valores de la libertad y la democracia, aunque a costa de la población indígena a la que no se le reconocía la posibilidad de civilizarse, virtud que también se le negaba a la población mexicana que los pioneros anglos encontraban en su camino. ${ }^{11}$ Para la corona de España y para la Iglesia, la frontera era tierra de bárbaros paganos a los que había que civilizar e incorporar al sistema político y económico. Para Estados Unidos, la frontera era tierra disponible para el primero que la ocupase, porque la ocupación por parte del indio o del mexicano no contaba. Estas dos clases de frontera las ha calificado un autor como fronteras de inclusión y fronteras de exclusión, respectivamente. ${ }^{12}$ El objetivo de la primera clase de frontera es la incorporación mediante la asimilación; el objetivo de la segunda es el desplazamiento o expulsión de la población indígena.

\section{LA HISTORIA COMO VARIABLE}

Aunque todo el pasado es historia, y el mayor número de fenómenos de frontera pertenece obviamente al pasado, la historia es una variable más. Me refiero al peso de la tradición, a la experiencia acumulada por los

\footnotetext{
11 Sobre la revisión crítica y la desmitificación del oeste que se está haciendo en los últimos años por los historiadores norteamericanos, especialmente los representantes de la llamada New Westem History, ver las citas y la bibliografía en Alfredo Jiménez (1996).

${ }^{12}$ Según Marvin W. Miksell (1959:62-74), las colonizaciones de romanos, árabes y españoles supusieron fronteras de inclusión: las colonizaciones de Canadá, Australia y Sudáfrica son ejemplos de fronteras de exclusión.
} 
pueblos, a la persistencia de los hechos o episodios sobre tiempos posteriores, sobre nuestro presente y sobre el futuro. En este sentido, hay fronteras que son hijas o consecuencia de la historia. Parece que algunas son hijas de un personaje, de un líder o héroe, aunque estos individuos son a su vez hijos de su tiempo y su cultura. La acción de hombres como Alejandro Magno o Hernán Cortés resultó creadora de fronteras. En tiempos más cercanos, Napoleón trastornó el mapa de Europa, aunque insisto en que esas fronteras nacionales no son las que aquí nos interesan.

Más significativo es el dato de las fronteras heredades de la historia. Muchas fronteras de la América indígena las heredó España, y después las distintas repúblicas. Todos los países con territorio en la cuenca amazónica tienen dentro de sus límites políticos verdaderos espacios de frontera. Brasil, por su extensión, es un caso extraordinario de fronteras que parecen pertenecer más al siglo XIX que a las vísperas del siglo XXI. Pero ninguna frontera ha resultado más compleja y dinámica que la heredada por México en compañía de Estados Unidos. El norte de la república mexicana y el suroeste de la Unión es hoy, más que nunca, un espacio de frontera con un origen histórico claro y una combinación de variables prácticamente inigualables en número y diversidad.

De la misma manera que se habla de historia política, económica, social o religiosa, las fronteras pueden también definirse en relación con alguna actividad sobresaliente, aunque estas divisiones sean siempre convencionales y sólo a efectos de análisis, porque la realidad no admite compartimentos. La rica experiencia en fronteras del continente americano en los últimos cinco siglos permite establecer tipos en razón de ciertas variables que son aspectos o subsistemas del sistema cultural. En la América española se han definido fronteras en relación con la actividad dominante y/o con la institución que encarnaba dicha actividad. Frontera de guerra, frontera misionera, minera, agrícola, comercial... son tipos que se han dado simultáneamente o de manera sucesiva. ${ }^{13}$ En definitiva, fronteras en la historia, o la historia vista y contada desde la perspectiva de la frontera.

\section{RECAPITULACIÓN Y REFLEXIONES}

La frontera es uno de los fenómenos más universales en la historia. Está en los orígenes, en la evolución y en el presente de la humanidad, y lo estará en su futuro. Expresiones como "un mundo sin fronteras" sólo son,

13 Ver sobre esta cuestión Guillermo Céspedes (1983), capítulo 5; James Lockhart y Stuart B. Schwartz (1983), capítulo 8. W. J. Eccles (1983) presenta otra frontera en América, la canadiense, y distingue tres periodos, el primero basado en el comercio de pieles: The Fur Trade Frontier, 1663-1700. 
lamentablemente, hermosas palabras para expresar hermosos deseos, porque los espacios fronterizos seguirán existiendo, y en ellos se darán, como en el pasado, situaciones de violencia e injusticia. No obstante, se ha aplicado en este ensayo una definición neutra de frontera como espacio de encuentro e interacción de gentes diferentes, sin prejuzgar las causas ni los efectos del encuentro. En este sentido, es también justo admitir que la humanidad siendo única es diversa, y las fronteras actúan como espacio de comunicación e intercambio que enriquece a las partes y estimula la inventiva.

Los fenómenos de frontera son una experiencia por analizar, y una realidad a considerar por los que tienen especial responsabilidad en el presente y futuro de una sociedad global, pero heterogénea. En contraste con la comunicación planetaria conseguida por la técnica, las fronteras han proliferado en los últimos tiempos y los conflictos fronterizos se han agravado, en parte como consecuencia del avance tecnológico. Se ha producido una extensión y un incremento de lo que en antropología se conoce como "privación relativa". Cada día son más las poblaciones que conocen la existencia de otros mundos, otros niveles y formas de vida, sin existir contacto físico. Los medios de comunicación electrónicos están creando espacios de frontera virtual. Campesinos que contemplan de lejos la ciudad, y pueblos del llamado tercer mundo, separados por océanos, se sienten hoy más pobres, más oprimidos, más infelices porque han descubierto todo lo que tienen los otros, todo lo que les sobra a los habitantes de los países desarrollados. En términos relativos, se sienten más pobres ahora que no existen las fronteras de la comunicación, pero se mantienen y refuerzan las fronteras de la pobreza y la injusticia.

En nuestra sociedad global, las fronteras virtuales y reales proliferan como nunca y sus ritmos de evolución superan previsiones y programas. Las escalas son muy diversas, desde el éxodo del campo a la ciudad hasta el salto de un continente a otro. África se dirige de manera creciente a Europa, y los enclaves de población musulmana (árabe o negra) son ya importantes en países como Francia. Es la revancha de las antiguas colonias contra las potencias coloniales. Dentro de los límites nacionales, y como fenómeno especialmente vigoroso en América Latina, el fenómeno de frontera se ha invertido en buena medida. Si en el oeste norteamericano la abundancia de tierra fue una válvula de escape para los descontentos o los desesperados, la migración en América Latina marcha del campo a las grandes urbes, donde se crean verdaderas fronteras con todas sus connotaciones negativas. Las megalópolis iberoamericanas, y de otros continentes, no son válvulas de escape o seguridad; por el contrario, se están convirtiendo en trampas y peligrosas bombas de tiempo. Estas situaciones 
llevan a la ampliación del concepto de frontera para incluir procesos de interacción de grupos diferenciados por lengua, creencias, valores, economía o estatus sociopolítico que comparten en sentido literal un mismo espacio geográfico. Es el tipo más sutil de frontera, porque los límites no son físicos sino socioculturales, y las barreras están en la mentalidad colectiva y no tanto en las leyes, que pueden ser comunes para todos, pero no funcionan con equidad en la práctica. Ejemplos: los hispanos que son ciudadanos de los Estados Unidos; los campesinos indígenas de América Latina; los residentes legales procedentes de África y asentados en París o Marsella.

Pero volvamos a la teoría y al método, que siempre son un refugio cómodo para los académicos en medio de una sociedad global plagada de conflictos reales. Se ha dicho con toda razón que las fronteras - allí donde gentes de culturas diferentes interactúan unas con otras y con el espacio físico- contienen tantas variables medioambientales, incluyendo distintos momentos a lo largo del tiempo, que son siempre únicas (Weber y Rausch, 1994:xxiii). Pero entre lo único y lo universal hay niveles intermedios, que convenientemente ordenados nos ayudan a entender los casos particulares y el fenómeno general, como se decía al principio. Este objetivo justifica la elaboración de tipologías como medio y no como fin. Parafraseando la fórmula clásica del periodismo, el investigador debe plantearse ante los fenómenos de frontera las preguntas básicas del profesional ante la noticia: quiénes, dónde, cuándo, por qué (las cuatro $\mathrm{v}$ dobles del inglés: who, where, when, why), más cómo y por cuánto tiempo. Estas y otras interrogantes están fuertemente ligadas a variables que actúan como racimos (clusters) en una dinámica de ida y vuelta, porque las causas producen efectos, y los efectos actúan sobre las causas.

Apuntemos algunos ejemplos. Los grandes periodos de la historia son un primer paso para agrupar fronteras: las de la antigüedad clásica en la civilización occidental; las que surgen en los tiempos modernos como parte del llamado Renacimiento; las que van de la mano de la Revolución Industrial; las fronteras del mundo de hoy. En las Américas, hay diferencias objetivas suficientes para distinguir las fronteras prehispánicas o precolombinas de las fronteras coloniales y neocoloniales. Cada gran civilización ha creado sus fronteras: la judeo-cristiana u occidental, la islámica, las orientales. Dentro de la civilización occidental, la expansión colonial inglesa es distinta de la española y portuguesa, y estas dos son variables de la expansión ibérica. Las grandes zonas climáticas del mundo guardan una significativa relación con las fronteras imperiales. España, por motivos bien conocidos, se concentró en el trópico americano, sin 
ignorar otras regiones. Pero, en cualquier caso, las fronteras tropicales tienen su singularidad respecto de otras latitudes, sea en América, África o Asia.

En conclusion, hay categorías objetivas que utilizadas como variables sirven para agrupar casos que sin dejar de ser únicos, comparten notas comunes. Estas agrupaciones permiten un cierto control de la multitud de variables que intervienen en los fenómenos de frontera. Pero no olvidemos que las tipologías son solamente un instrumento de trabajo, y la adscripción de una frontera concreta a un tipo determinado es una elaboración subjetiva y de valor relativo. Y otra advertencia: en la interpretación de los fenómenos-de frontera es especialmente notable la tentación de forzar los hechos para que se acomoden a modelos y estereotipos de una tradición histórica abundante en prejuicios culturales y nacionales.

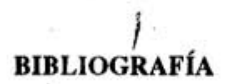

BILLINGTON, Ray Allen. 1966. Americas Frontier Heritage. Holt, Rinehart, and Winston. Nueva York.

CÉSPEDES, Guillermo. 1983. América hispánica, 1492-1898. Editorial Labor. Barcelona.

ECCLES, Walter J. 1983. The Canadian Frontier, 1534-1760. University of New Mexico Press. Albuquerque, N.M.

JIMÉNEZ, Alfredo. 1996. "El lejano norte español: cómo escapar del American West y de las Spanish Borderlands", Colonial Latin American Historical Review, vol. 5, núm. 4:381-412.

- 1997a. Antropología historica: la Audiencia de Guatemala en el siglo XVI. Universidad de Sevilla.

- 1997b. "La frontera en América: observaciones críticas y sugerencias", en Justina Sarabia Viejo et al. (eds.), Entre Puebla de los Ángeles y Sevilla. Estudios americanistas en homenaje al Dr. José Antonio Calderón Quijano: 475-494. Escuela de Estudios HispanoAmericanos y Universidad de Sevilla. Sevilla.

KUTSCHE, Paul. 1983. "Borders and Frontiers" en Ellwyn R. Stoddard, et al. (eds), Borderlands Sourcebook. A Guide to the Literature on Northern Mexico and the Southwest. University of Oklahoma Press, Norman, Oklahoma.

LOCKHART, James y Stuart B. Schwartz. 1983. Early Latin America. A History of Colonial Spanish America and Brazil. Cambridge University Press. 
MIKSELL, Marvin W. 1959. "Comparative Studies in Frontier History", Annals of American Geographers, vol. 49:62-74.

POWELL, Philip Wayne. 1952. Soldiers, Indians, \& Silver. The Northward Advance of New Spain, 1550-1600. University of California Press.

TURNER, Frederick Jackson. 1894. "The Significance of the Frontier in American History", Annual Report of the American Historical Association: 199-227. Washington, D.C.

WEBB, Walter Prescott. 1952. The Great Frontier. Houghton Mifflin Co. Boston.

WEBER, David J. 1992. The Spanish Frontier in North America. Yale University Press.

WEBER, David J. y Jane M. Rausch (eds.). 1994. Where Cultures Meet. Frontiers in Latin American History. Jaguar Books on Latin America, núm. 6. Scholarly Resources Books. Wilmington, Delaware. 